\title{
Experimental Study on the Process of Evaluation in University Tennis Teaching
}

\author{
Yuwang ZHANG \\ China University of Geosciences(BEI JING) Physical Education department
}

\begin{abstract}
In this paper, by using the method of questionnaire, teaching experiment, logical analysis and mathematical statistics, the process evaluation of our 4 Boys Junior tennis classes was studied. The experimental results show that, the process of evaluation in the teaching of tennis transfer from the focus on students' learning results to pay more attention to students' learning process, evaluation of student learning is more objective, comprehensive and timely. It can not only give full play to students' personality, cultivate students' Autonomous Learning ability, and make students form the cooperative learning atmosphere, establish cooperation relationship, more conducive to improving teaching effect. Compared with the control group at the end of the semester, students in the experimental group can significantly enhance students' the short distance sprint ability, lower extremity bouncing, upper body strength and flexibility, but also in the 50 meter dash and pull-up are increased more significantly; the level of tennis technique is better than that of the control group; there are significant differences in learning attitude and the spirit of cooperation, affective performance level.
\end{abstract}

KEYWORD: colleges; tennis teaching; process evaluation; difference

Promulgated in 2002 "national ordinary university school sports curriculum teaching instruction summary" requirements of college PE course learning content is divided into sports participation, sports skills, physical health, mental health and social adaptation and so on five learning areas, and its evaluation content includes the students' physical fitness, knowledge, skills, learning attitude, emotion and spirit of cooperation, the evaluation index from the past single movement skills widen to physical ability, knowledge and skills, learning attitude, emotion and spirit of cooperation, etc. The evaluation indexes and the existing evaluation indexes both quantitative evaluation, and qualitative evaluation. The construction of a new system in our country school sports teaching goal marked the sports teaching in training talents in colleges and universities in the new period of diverse mission. However, at present, the traditional way of summative evaluation of sports in PE teaching in colleges and universities has a deep-rooted influence, only pay attention to the students' sports level, can not fully reflect the sports fitness and education functions such as nature, often severely dampened the enthusiasm of students to participate in physical exercise, and affected the improvement of teaching quality, thus to explore of the science of physical education teaching in colleges and universities evaluation method is particularly important. Under this background this article explores the option class in our school tennis teaching implementation process in the evaluation of the content and operating procedures, in order to dynamically control technological learning process of students, so as to improve the enthusiasm of students to exercise is beneficial to realize the sports teaching of middle school students as the main body, teacher as the leading new pattern of teaching, improve teaching quality effectively.

\section{THE OBJECT OF STUDY AND RESEARCH METHODS}

\subsection{The object of study}

This article selects 2012 junior school year 2nd semester four boys tennis as the research object, all subjects without any tennis technology base.

\subsection{The research methods}

\subsubsection{Of literature}

Widely consult about psychology, pedagogy and 
education evaluation, evaluation of sports and tennis teaching evaluation and other related articles, books, understand this topic research present situation and tendency, and the related data collection and analysis.

\subsubsection{Questionnaire investigation}

According to the research purpose and content, this paper design "the ordinary university tennis teaching process evaluation index screening questionnaire". Beijing is engaged in the research of tennis teaching physical education teachers in university, to determine the content of student achievement evaluation of different dimensions.

\subsubsection{Teaching experimental method}

Test time: March to June in 2013.

Experimental control: randomly selected two classes as experimental group with 68 people; 2 class for the control group with 64 people. Before the trial was carried out on the experimental group and the control-group students body quality initial level testing, to eliminate the influence of the independent variables.

According to the result of expert evaluation, the first set experimental procedural student performance evaluation system: including three parts: selfevaluation of students, students mutual, teacher evaluation. Design "the college tennis special class students learning attitude, affective expression and cooperation spirit questionnaire". In order to ensure the validity of the questionnaire, once again to Beijing colleges and universities sports education expert questionnaire, according to the opinions of the experts to modify the problem of the questionnaire and finishing, questionnaire items listed and classified structure has high validity. Then issue the revised questionnaire for the experimental group and the control group students. Questionnaire after recovery, 15 students in the experimental group and control group randomly, retest reliability inspection with the result of the two related inspection, correlation coefficient $r=0.87$.

Teachers guide and supervise to the students' selfevaluation, mutual process and methods. Every 5 weeks on a periodic evaluation, phased evaluation content, evaluation study manner, the cordiality performance and the cooperation spirit, technology evaluation, a total of 2 times. The teacher wants to in a timely manner will result feedback and evaluation to the students, let students immediately understand their own learning situation, the result of the According to the evaluation of student performance to evaluate content again at the end of the semester. Student achievement evaluation content: basic physical fitness test, tennis technical test, learning attitude and cordiality cooperation performance evaluation, and formulate the corresponding evaluation criteria at the end of the semester.
Control group with the traditional one-time summative evaluation. The experimental group and the control group at the end of the semester student achievement evaluation content exactly the same.

\subsubsection{Logic analysis}

With the result of the experiment, experiment paper summarizes problems arising from the use of logic theory and contrastive analysis.

\subsubsection{Data statistics}

Make use of Excel XP and SPSS17.0 statistical analysis and process for the experimental data.

\section{THE RESULTS OF THE STUDY AND ANALYSIS}

Process evaluation is since the 1980s, gradually formed a kind of evaluation model, the evaluation is to point to in the process of curriculum implementation way to evaluate students' learning, evaluation and more flexible way, its basic idea is to implement evaluation in learning, to promote learning in the evaluation, provide feedback of teaching, so as to continuously improve and perfect teaching. It argues that evaluation process and the teaching process of crossover and integration, take aim and process of value orientation, to student's learning process, effects, and closely related to learning non-intelligence factors comprehensive evaluation, is a kind of internal and external combination, open a way of evaluation. Compared with the traditional summative evaluation, process evaluation on the evaluation function and the core of all significant changes have taken place, is not only pay attention to the result of evaluation, and more attention to students' learning process evaluation, and emphasizing the goals and process.

\subsection{Do physical fitness index tests and statistical tests at the beginning of the semester for the experimental group and the control group students}

The beginning of the semester, five of the experimental group and the control group students physical fitness index and learning attitude and cooperation of affection index test, $T$ test was carried out on the test scores (see table 1,2), the results showed that four class of students' physique level and learning attitude an d cordiality spirit of cooperation, there was no significant difference on statistics can be thought of from the same overall, conform to the requirements of the teaching experiment statistical grouping. 
Table 1 semester of the experimental group and the control group students' five measures of physical difference comparison

\begin{tabular}{|c|c|c|c|c|c|c|c|c|c|c|}
\hline \multirow[t]{2}{*}{ Groups } & \multicolumn{2}{|c|}{$50 \mathrm{~m}$ Jogging $(\mathrm{s})$} & \multicolumn{2}{|c|}{ Standing Vertical Jump $(\mathrm{cm})$} & \multicolumn{2}{|c|}{$1000 \mathrm{~m}(\mathrm{~min})$} & \multicolumn{2}{|c|}{ Chin-up (times) } & \multicolumn{2}{|c|}{ Sit and $\operatorname{Reach}(\mathrm{cm})$} \\
\hline & $\mathrm{x}$ & $\mathrm{s}$ & $\mathrm{x}$ & $\mathrm{s}$ & $\mathrm{x}$ & $\mathrm{s}$ & $\mathrm{x}$ & $\mathrm{s}$ & $\mathrm{x}$ & $\mathrm{s}$ \\
\hline Experimental group & 7.3 & 0.48 & 47 & 5.1 & 3.57 & 0.23 & 13.2 & 2.24 & 12.04 & 2.51 \\
\hline In the control group & 7.4 & 0.42 & 48 & 5.3 & 3.55 & 0.27 & 13.1 & 2.13 & 12.21 & 2.32 \\
\hline T test & \multicolumn{2}{|c|}{1.2543} & \multicolumn{2}{|c|}{1.1034} & \multicolumn{2}{|c|}{0.4568} & \multicolumn{2}{|c|}{0.2629} & \multicolumn{2}{|c|}{0.4043} \\
\hline $\mathrm{P}$ & \multicolumn{2}{|c|}{$\mathrm{P}>0.20$} & \multicolumn{2}{|c|}{$\mathrm{P}>0.20$} & \multicolumn{2}{|c|}{$\mathrm{P}>0.20$} & \multicolumn{2}{|c|}{$\mathrm{P}>0.20$} & \multicolumn{2}{|c|}{$\mathrm{P}>0.20$} \\
\hline
\end{tabular}

Table 2 before the trial group and control group in students' learning attitude and cordiality cooperation index difference comparison

\begin{tabular}{|c|c|c|c|c|}
\hline Evaluation Content & Experimental group & In the control group & T test & P \\
\hline Learning attitude & $65.1 \pm 5.8$ & $64.7 \pm 5.4$ & 0.4103 & $\mathrm{P} 0.2$ \\
\hline Affective cooperation & $63.2 \pm 6.7$ & $62.5 \pm 5.3$ & 0.6677 & $\mathrm{P} 0.2$ \\
\hline
\end{tabular}

2.2 The experimental group and the control group before and after the semester students different physical indicators of comparative analysis.

In order to explore the process of evaluation on students' fitness levels, in this paper, the experimental group and the control group before and after the semester students different physical indicators for comparative analysis. Table 3 shows that in addition to 1000 meters, the rest of the four indexes of the experimental group students have very significant difference. This shows that in our school tennis teaching implementation process in the evaluation of teaching experiment, the teaching effect is better, can significantly enhance the students' ability of short sprints, jumping ability of lower limbs, upper body strength and body flexibility, the fitness level is necessary to play tennis sports.

Below we analyze the four significant indicators: 50 meters belongs to short time, large strength test project, the power supply way as the original phosphate system, which is very similar with the characteristics of tennis and supply can, tennis is a kind of composed of continuous explosive action for a short period of time sports, students need a quick judgment in practice, quick, fast moving, fast, basically is a kind of anaerobic lactic acid. The influences of tennis power quality mainly include the student's upper body strength and strength of lower limbs. Reaction of the upper body strength pull-ups, upper body strength on its performance is more important, this is because the tennis rackets and balls are relatively heavy, if students do not have upper limbs strength quality, the practice cannot play big ball speed and damage, at the same time practice is often caused by power enough to exercise fatigue. In situ vertical jump test is mainly used to test students' coordination and explosive in the legs. Tennis every action is from leg to begin with, leg rapid start ability in tennis technology plays an important role in practice. ZuoWeiTi proneness indexes reflecting the abdominal muscles flexible force in maintaining balance and strength in the tennis match has a very important role. It not only can promote the increase of the range of motion, strengthened the ability of movement to push accuracy, and can effectively avoid muscle, ligament injury.

Group of five physical qualities, only the impact on the endurance quality did not reach significant, probably because for beginners of tennis teaching, mainly single technology and simple combination practice, actual combat part teaching is less, students didn't get in endurance quality improved significantly.

Table 4 results show that the term that in comparative classes students before and after physical indicators of progress in the same as the experimental class, in 50 meters, pull-ups show very significant difference in the two indicators, such as in situ vertical jump and ZuoWeiTi proneness show significant differences in the two indicators. No significant difference reflects the endurance index of the 1000 - meter run.

Table 3 Semester before and after comparing different physical indexes of the differences between the experimental group students

\begin{tabular}{|c|c|c|c|c|c|c|c|c|c|c|}
\hline Experimental group & \multicolumn{2}{|c|}{$\begin{array}{c}\text { 50m Jogging } \\
(\mathrm{s})\end{array}$} & \multicolumn{2}{|c|}{$\begin{array}{c}\text { Standing Vertical } \\
\text { Jump (cm) }\end{array}$} & \multicolumn{2}{|c|}{$\begin{array}{c}1000 \mathrm{~m} \\
(\mathrm{~min})\end{array}$} & \multicolumn{2}{|c|}{$\begin{array}{l}\text { Chin-up } \\
\text { (times) }\end{array}$} & \multicolumn{2}{|c|}{$\begin{array}{c}\text { Sit and Reach } \\
(\mathrm{cm})\end{array}$} \\
\hline & \multicolumn{2}{|c|}{$\mathrm{x}$} & \multicolumn{2}{|c|}{$\mathrm{S}$} & \multicolumn{2}{|c|}{$\mathrm{x}$} & \multicolumn{2}{|c|}{$\mathrm{s}$} & \multicolumn{2}{|c|}{$\mathrm{x}$} \\
\hline Before the semester & 7.3 & 0.48 & 47 & 5.1 & 3.57 & 0.23 & 13.2 & 2.24 & 12.04 & 2.51 \\
\hline Semester & 7.0 & 0.23 & 51 & 4.3 & 3.53 & 0.21 & 15.1 & 1.32 & 13.18 & 1.78 \\
\hline T test & \multicolumn{2}{|c|}{4.6209} & \multicolumn{2}{|c|}{4.9446} & \multicolumn{2}{|c|}{1.0590} & \multicolumn{2}{|c|}{6.0261} & \multicolumn{2}{|c|}{3.0550} \\
\hline $\mathrm{P}$ & \multicolumn{2}{|c|}{$\mathrm{P} \quad 0.01$} & \multicolumn{2}{|c|}{$\mathrm{P} \quad 0.01$} & \multicolumn{2}{|c|}{$\mathrm{P} \quad 0.20$} & \multicolumn{2}{|c|}{$\mathrm{P} \quad 0.01$} & & \\
\hline
\end{tabular}


Table 4 Semester before and after comparing different physical indexes of the differences between the control group students

\begin{tabular}{|c|c|c|c|c|c|c|c|c|c|c|}
\hline In the control group & \multicolumn{2}{|c|}{$\begin{array}{c}\text { 50m Jogging } \\
(\mathrm{s})\end{array}$} & \multicolumn{2}{|c|}{$\begin{array}{l}\text { Standing Vertical } \\
\text { Jump }(\mathrm{cm})\end{array}$} & \multicolumn{2}{|c|}{$\begin{array}{c}1000 \mathrm{~m} \\
(\mathrm{~min})\end{array}$} & \multicolumn{2}{|c|}{$\begin{array}{l}\text { Chin-up } \\
\text { (times) }\end{array}$} & \multicolumn{2}{|c|}{$\begin{array}{l}\text { Sit and Reach } \\
(\mathrm{cm})\end{array}$} \\
\hline & \multicolumn{2}{|c|}{$\mathrm{x}$} & \multicolumn{2}{|c|}{$\mathrm{s}$} & \multicolumn{2}{|c|}{$\mathrm{x}$} & \multicolumn{2}{|c|}{$\mathrm{s}$} & \multicolumn{2}{|c|}{$\mathrm{x}$} \\
\hline Before the semester & 7.4 & 0.42 & 48 & 5.3 & 3.55 & 0.27 & 13.1 & 2.13 & 12.21 & 2.32 \\
\hline Semester & 7.2 & 0.33 & 50 & 4.1 & 3.54 & 0.247 & 14.2 & 1.78 & 13.11 & 2.08 \\
\hline $\mathrm{T}$ test & \multicolumn{2}{|c|}{2.9954} & \multicolumn{2}{|c|}{2.3877} & \multicolumn{2}{|c|}{0.2214} & \multicolumn{2}{|c|}{3.1702} & \multicolumn{2}{|c|}{2.3107} \\
\hline $\mathrm{P}$ & \multicolumn{2}{|c|}{$\begin{array}{ll}\mathrm{P} & 0.01\end{array}$} & \multicolumn{2}{|c|}{$\mathrm{P} \quad 0.05$} & \multicolumn{2}{|c|}{$\begin{array}{ll}\mathrm{P} & 0.20\end{array}$} & \multicolumn{2}{|c|}{$\begin{array}{ll}\mathrm{P} & 0.01\end{array}$} & \multicolumn{2}{|c|}{$\mathrm{P} \quad 0.05$} \\
\hline
\end{tabular}

Table 5 semester students in the experimental group and the control group five physical indicators compare differences

\begin{tabular}{|c|c|c|c|c|c|c|c|c|c|c|}
\hline \multirow[t]{2}{*}{ Groups } & \multicolumn{2}{|c|}{$\begin{array}{c}\text { 50m Jogging } \\
(\mathrm{s})\end{array}$} & \multicolumn{2}{|c|}{$\begin{array}{c}\text { Standing Vertical } \\
\text { Jump }(\mathrm{cm})\end{array}$} & \multicolumn{2}{|c|}{$\begin{array}{c}1000 \mathrm{~m} \\
(\mathrm{~min})\end{array}$} & \multicolumn{2}{|c|}{$\begin{array}{l}\text { Chin-up } \\
\text { (times) }\end{array}$} & \multicolumn{2}{|c|}{$\begin{array}{l}\text { Sit and Reach } \\
(\mathrm{cm})\end{array}$} \\
\hline & $\mathrm{x}$ & $\mathrm{s}$ & $\mathrm{x}$ & $\mathrm{s}$ & $\mathrm{x}$ & $\mathrm{s}$ & $\mathrm{x}$ & $\mathrm{s}$ & $\mathrm{x}$ & $\mathrm{s}$ \\
\hline Experimental group & 7.0 & 0.23 & 51 & 4.3 & 3.53 & 0.21 & 15.1 & 1.32 & 13.28 & 1.78 \\
\hline In the control group & 7.2 & 0.33 & 50 & 4.1 & 3.54 & 0.24 & 14.2 & 1.78 & 13.11 & 2.08 \\
\hline T test & \multicolumn{2}{|c|}{4.0164} & \multicolumn{2}{|c|}{1.3677} & \multicolumn{2}{|c|}{0.2541} & \multicolumn{2}{|c|}{3.2834} & \multicolumn{2}{|c|}{0.5031} \\
\hline $\mathrm{P}$ & \multicolumn{2}{|c|}{$\mathrm{P} \quad 0.05$} & \multicolumn{2}{|c|}{ P $\quad 0.2$} & \multicolumn{2}{|c|}{ P 0.2} & \multicolumn{2}{|c|}{$\mathrm{P} \quad 0.01$} & \multicolumn{2}{|c|}{ P 0.2} \\
\hline
\end{tabular}

Table 6 semester students in the experimental group and the control group 3 test specification differences

\begin{tabular}{|c|c|c|c|c|c|c|}
\hline \multirow[t]{2}{*}{ Groups } & \multicolumn{2}{|c|}{ Forehand } & \multicolumn{2}{|c|}{ Backhand } & \multicolumn{2}{|c|}{ Overhand Serve } \\
\hline & $\mathrm{x}$ & $\mathrm{s}$ & $\mathrm{x}$ & $\mathrm{s}$ & $\mathrm{x}$ & $\mathrm{s}$ \\
\hline Experimental group & 6.89 & 1.21 & 5.79 & 1.15 & 5.92 & 1.41 \\
\hline In the control group & 6.45 & 1.28 & 5.42 & 0.93 & 5.20 & 1.33 \\
\hline $\mathrm{T}$ experiment & \multicolumn{2}{|c|}{2.0267} & \multicolumn{2}{|c|}{2.0379} & \multicolumn{2}{|c|}{3.0190} \\
\hline $\mathrm{P}$ & \multicolumn{2}{|c|}{$\mathrm{P} \quad 0.05$} & \multicolumn{2}{|c|}{$\mathrm{P} \quad 0.05$} & \multicolumn{2}{|c|}{$\mathrm{P} \quad 0.01$} \\
\hline
\end{tabular}

Table 7 semesters before and after the experimental group of students learning attitude and affection cooperation indicators compare differences

\begin{tabular}{|c|c|c|c|c|c|c|c|}
\hline \multirow{2}{*}{ norm } & \multicolumn{3}{|c|}{ Experimental group } & \multicolumn{3}{c|}{ In the control group } & \multicolumn{2}{c|}{ After the } \\
\cline { 2 - 8 } & Before the semester & Semester & $\mathrm{T}$ & Before the semester & Semester & $\mathrm{T}$ & experiment T \\
\hline Learning Attitude & $65.1 \pm 5.8$ & $72.3 \pm 4.9$ & $7.8196^{* *}$ & $64.7 \pm 5.4$ & $70.2 \pm 4.4$ & $6.2018^{* *}$ & $2.7171^{* *}$ \\
\hline Affection Cooperation & $63.2 \pm 6.7$ & $71.1 \pm 5.0$ & $7.7925^{* *}$ & $62.5 \pm 5.3$ & $69.1 \pm 4.2$ & $8.2810^{* *}$ & $1.9949 * *$ \\
\hline
\end{tabular}

\subsection{Comparative analysis semester students in the experimental group and the control group of different technical indicators}

After a semester of teaching tennis, end of the semester for students' three technical indicators tests, forehand, backhand shot by students near the midpoint of the teachers at the bottom of the net at the tee, the ball in the singles line effective ball, each student were playing 10 balls. Overhand Serve test method was a student at the left and right of each district's success made the number five goals. T-test for test results (see Table 6), indicating that the experimental group and the control group of students the basic skill levels of tennis scores mean a very significant or significant differences, indicating that students in the experimental class ball judgment, footwork moves racket control and other aspects of hitting power than the control classes.

\subsection{Compare and analysis of attitudes and feelings of cooperation indicators of the experimental group and control group students}

Learning attitude directly affects student learning enthusiasm, sports learning attitude is that students of sports activities held by some evaluation, experience and behavioral tendencies, and overall performance. Learning attitude assessment indicators include learning objectives, learning interest, participation, effort. As can be seen from Table 7, the experimental group and control group students learning attitude in tennis technology has progressed significantly. The experimental class students to compare and contrast class, learning attitude more apparent progress, the two have significant differences, indicating that the process of evaluation so that students feel that they are learning the subject, not only to stimulate enthusiasm for learning and personality development of students, but also students learn to learn, to learn more efforts to actively. The traditional methods of evaluation of 
student effort, feedback and evaluate the progress of magnitude, which to some extent affected the students' enthusiasm.

T-test can be seen from Table 7 after the experiment after experiment in the experimental group and a control group of students there are very significant differences $(\mathrm{P}<0.01)$ in the expression of affection and cooperation spirit level, indicating that the process of evaluation of the use of the experimental classes affection performance and significant progress in a spirit of cooperation to promote the role of the students to form a cooperative learning environment, learning selfconfidence has been greatly satisfied.

\section{CONCLUSIONS AND RECOMMENDATIONS}

1. Assessment process used in the teaching of college tennis, the results from a focus on student learning transfer to pay more attention to students' learning process, students evaluate the contents included physical, skills, attitudes and psychological evaluation study of emotion, evaluation of student learning more objective, comprehensive, timely, that will help the student individuality, self-learning ability of students to improve teaching effectiveness.

2. Semester students in the experimental group and the control group were significantly enhance students' ability to sprint, leg jumping ability, upper body strength and flexibility, the experimental group was significantly greater in the two $50 \mathrm{~m}$ run and pull upward increase margin targets.

3. Semester students in the experimental group than the control class tennis technique. The experimental group and the control group of students there is a very significant difference in learning attitude, affective expression and spirit of cooperation level

4. Experiments illustrate the process of evaluation allows students to feel that they are learning the subject, not only to stimulate the students' enthusiasm and personality development, but also to enable students to form a cooperative learning good atmosphere.

5. Recommends more sports educators in teaching practice for more demonstration project evaluation process, to further improve the process evaluation system, the implementation steps.

\section{REFERENCES}

[1] Xiao Yuan Jun Educational Assessment Principles and Applications Zhei Jiang: Zhei Jiang University Press, 2004.

[2] Sports Science psychological rating scale commonly used manual [2] tension, etc. Beijing: Beijing Sports University Press .2004.

[3] Weixin Sun .Tennis modern satellite technology teaching. Beijing: Beijing Sports University Press, 2007.

[4] Zhang Ling, Marsanne, Yuzhu Li physical education should be implemented by the end of the evaluation process of the transfer to the evaluation Physical Education, 2000, (6): 8789.

[5] Pengqing Jun, Zhu Lingling University study sports learning evaluation model Shandong Sports Science, 2005, (3): 8182.

[6] Huayin. Explore college sports learning process evaluation Wuhan Institute of Physical Education, 2005, (4): 111-112.

[7] Shi Songtao. The ues of process evaluation in physical teaching. Anhui Sports Science, 2004, (5), 123-124.

[8] Han Jian: the importance of the process of evaluation Nan Jing Institute of Physical Education, 2004, (5): 98-99.

[9] Chunyan Yu. In college sports study the feasibility of learning evaluation system reform sports world, 2006, (3): 36-39. 